\title{
Keanekaragaman Serangga Air di Sungai Pajowa Kabupaten Minahasa, Sulawesi Utara
}

\author{
Gladyes V. Lebaa*, Roni Koneria, Adelfia Papua \\ aJurusan Biologi, FMIPA, Unsrat, Manado
}

\section{K A T A K U N C I}

Keanekaragaman

Serangga Air

Sungai Pajowa

Sulawesi Utara

\section{KEYW OR D S}

Biodiversity

Water Insects

Pajowa River

North Sulawesi

\section{AVAILABLE ONLINE} 17 Juni 2013

\begin{abstract}
A B S T R A K
Serangga air merupakan kelompok Arthropoda yang sebagian siklus hidupnya berada di perairan. Serangga ini berperan penting dalam rantai makanan pada suatu ekosistem perairan. Penelitian ini bertujuan untuk menganalisis kelimpahan, kekayaan, keanekaragaman dan kemerataaan spesies serangga air di Sungai Pajowa, Kabupaten Minahasa, Sulawesi Utara. Pengambilan sampel menggunakan surber sampler dan hand collection. Jumlah serangga air yang ditemukan sebanyak 22 spesies, 14 famili dan 5 ordo. Spesies yang paling banyak ditemukan adalah Gerris remigis, sedangkan ordo yang memiliki spesies paling banyak adalah Ephemeroptera. Kelimpahan dan kekayaan spesies serangga air tertinggi terdapat pada bagian tengah aliran sungai, sedangkan keanekaragaman dan kemerataan spesies tertinggi di bagian hulu sungai. Kelimpahan, kekayaaan dan keanekaragaman spesies serangga air berbeda nyata antar stasiun pengamatan, sedangkan kemerataan spesies tidak menunjukkan perbedaan yang nyata.

A B S T R A C T

Arthropods are a group of aquatic insects whose life cycles are partly in the water. These insects play an important role in the food chain in an aquatic ecosystem. This research is aimed to analyze the abundance, richness, diversity and evenness of species of insects in the river water Pajowa, Minahasa regency, North Sulawesi. Surber sampler and hand collection are used in Sampling. Number of aquatic insects found as many as 22 species, 14 families and 5 orders. The most commonly found species is Gerris remigis, while orders that have the most species are Ephemeroptera. Abundance and species richness of aquatic insects is highest in the middle of the river, while the highest species diversity and evenness in the upper reaches of the river. Abundance, species richness and diversity of aquatic insects were significantly different between the stations of observation, whereas species evenness did not show significant differences.
\end{abstract}

\section{Pendahuluan \\ Sungai Pajowa merupakan salah satu sungai yang termasuk dalam kawasan Kabupaten Minahasa Sulawesi Utara. Sungai tersebut berperan penting bagi masyarakat sekitarnya. Semakin ke arah hilir sungai, terjadi perubahan fungsi lahan di daerah aliran sungai seperti pemukiman dan pertanian. Kegiatan ini dapat menyebabkan penurunan kualitas air sungai yang akan}

mengakibatkan terjadinya perubahan fisik dan kimia air seperti suhu, oksigen terlarut, pH, Fosfat, Nitrat, dan konsentrasi logam. Perubahan tersebut dapat ikut mempengaruhi keberadaan organisme akuatik di perairan, dan ikut berdampak terhadap kelimpahan dan keanekaragaman serangga yang menempati ekosistem perairan tersebut.

Pada ekosistem perairan serangga air berperan dalam siklus nutrisi dan merupakan komponen penting dari jaring-jaring makanan di 
perairan (Jana et al., 2009). Beberapa spesies sangat rentan dan sensitif terhadap pencemaran lingkungan, sedangkan yang lainnya dapat hidup dan berkembang biak pada kondisi perairan yang tercemar (Popoola and Otalekor, 2011). Sehingga dapat dijadikan sebagai indicator untuk menguji kualitas air.

Secara visual, keadaan sungai Pajowa semakin ke hilir mulai memperlihatkan turunnya kualitas air, disebabkan adanya aktivitas penduduk sekitarnya. Berdasarkan kondisi tersebut maka, perlu diadakan pembuktian secara ilmiah dengan dilakukannya penelitian. Apalagi penelitian dan publikasi menyangkut keanekaragaman serangga air di Sungai Pajowa belum pernah dilaksanakan dan dipublikasikan. Penelitian ini bertujuan untuk menganalisis kelimpahan, kekayaan, keanekaragaman dan kemerataan spesies serangga air di sungai Pajowa, Kabupaten Minahasa Sulawesi Utara. Data yang di peroleh diharapkan dapat bermanfaat sebagai database keanekaragaman serangga air di Sulawesi Utara dan sebagai bahan kajian dalam konservasi keanekaragaman hayati khususnya serangga air di Sungai Pajowa.

\section{Metode}

\subsection{Lokasi Penelitian}

Penelitian ini dilaksanakan di Sungai pajowa Kabupaten Minahasa Utara, pada bulan Juli sampai September 2012. Penentuan titik pengambilan sampel dilakukan pada lokasi yang terpilih berdasarkan hasil survei, dengan melihat kondisi sungai. Berdasarkan kondisi sungai tersebut maka

Penelitian ini dilaksanakan di Sungai Pajowa Kabupaten Minahasa Utara, pada bulan Juli sampai September 2012. Penentuan titik pengambilan sampel dilakukan pada lokasi yang tepilih berdasarkan hasil survey, dengan melihat kondisi sungai. Berdasarkan kondisi sungai tersebut maka ada tiga stasiun yang dijadikan sebagai lokasi pengambilan sampel, yaitu: bagian hulu sungai (stasiun 1), bagian tengah daerah aliran sungai (stasiun 2), dan bagian hilir sungai (stasiun 3). Pada masing-masing stasiun ditentukan sebanyak 4 titik pengamatan

Stasiun 1 terdapat di bagian hulu sungai. Sungai dangkal (kedalaman $11 \mathrm{~cm}-20,3 \mathrm{~cm}$ ), berbatu bersubstrat dasar pasir. Vegetasi tepi (riparian) yang ada di lokasi masih padat sehingga air tertutupi oleh kanopi pepohonan yang ada di sekitarnya. Tumbuhan yang ada di tepi sungai didominasi oleh berbagai jenis paku-pakuan, dan bambu. Pada stasiun ini terlihat belum banyak terjadi aktivitas dan aliran air sungai ini dimanfaatkan oleh warga sebagai sumber air bersih. Hal ini terlihat adanya bak penampungan air di bagian hulu sungai dan adanya pipa yang dipasang dari bak penampungan sampai ke rumah-rumah warga. Kecepatan arus sebesar 0,13 m/s. Suhu air berkisar antara $19{ }^{\circ} \mathrm{C}-20{ }^{\circ} \mathrm{C}$; BOD (Biochemical Oxygen Demand ) < 2; COD (Chemical Oxygen
Demand) < 10; D0 (Dissolved Oxygen) berkisar antara 7,82-7,86; dan $\mathrm{pH}=7$.

Stasiun 2 terdapat di bagian tengah daerah aliran sungai. Substrat berbatu dan berpasir. Tumbuhan yang ada di tepi sungai yaitu pakupakuan, bambu dan rumput. Di sekitar lokasi terdapat pemukiman penduduk dan banyak aktivitas yang memanfaatkan sungai, seperti irigasi, kegiatan mandi, cuci, dan kakus (MCK) dan juga terdapat sejumlah ternak yang hidup di sekitar lokasi, memanfaatkan air sungai untuk minum dan membuang limbah ternak di aliran sungai. Kedalaman sungai berkisar $23 \mathrm{~cm}-57,4 \mathrm{~cm}$ dan memiliki kecepatan arus $(0,23 \mathrm{~m} / \mathrm{s})$. Suhu air $22{ }^{\circ} \mathrm{C}$; BOD (Biochemical Oxygen Demand ) < 2; COD (Chemical Oxygen Demand) < 10; DO (Dissolved Oxygen) berkisar antara 7,34-749; dan $\mathrm{pH}=7$.

Stasiun 3 terdapat di bagian hilir sungai. Tumbuhan yang ada di tepi sungai didominasi oleh rumput, paku-pakuan dan padi (Oryza sativa). Pemanfaatan lahan sebagai pemukiman dan pertanian serta peternakan semakin jelas di daerah hilir sungai. Masyarakat sekitar juga membuang sampah di sekitar sungai bahkan di sungai. Sungai berarus tenang dengan kecepatan arus $0,08 \mathrm{~m} / \mathrm{s}$, dengan kedalaman sungai berkisar $36 \mathrm{~cm}-59 \mathrm{~cm}$ dan substrat dasar pasir berlumpur. Suhu air $24{ }^{\circ} \mathrm{C}$ $25^{\circ} \mathrm{C}$; BOD (Biochemical Oxygen Demand) < 2; COD (Chemical Oxygen Demand) < 10; DO (Dissolved Oxygen) berkisar antara 6,75-7,37; dan $\mathrm{pH}=7$.

\subsection{Teknik Pengambilan Sampel}

Penelitian ini menggunakan metode Purposive Random Sampling. Pada masing-masing stasiun ditentukan titik pengambilan sampel. Penentuan titik sampel berdasarkan keadaan lokasi penelitian yang memungkinkan untuk melakukan pengambilan serangga air dengan alat-alat yang telah disediakan. Pada setiap stasiun dibuat sebanyak empat titik pengambilan sampel. Total jumlah titik pengambilan sampel sebanyak 12 titik sampel. Teknik pengambilan sampel menggunakan hand collection dan surber sampler. Spesimen serangga air yang diperoleh dibersihkan kemudian dimasukkan kedalam botol sampel y ang berisikan larutan pengawet (alkohol 70\%). Sampel dibawa ke laboratorium kemudian diamati dengan menggunakan lup (kaca pembesar) dan mikroskop. Sampel kemudian diidentifikasi dan dihitung jumlah individunya. Identifikasi sampel mengacu pada buku-buku identifikasi Borror et al. (1992), Cutkomp (1992), Bugguide (2012), Wright (2003) dan Troutnut (2012).

\subsection{Analisis Data}

Analisis data meliputi kelimpahan spesies ( $n$ ), kekayaan spesies (s), nilai keanekaragaman spesies (H) dan nilai kemerataan spesies (E). Kelimpahan spesies merupakan jumlah individu setiap spesies yang ditemukan pada setiap titik pengambilan sampel. Kekayaan spesies didasarkan pada jumlah spesies yang hadir pada lokasi penelitian. Penentuan tingkat keanekaragaman spesies 
menggunakan indeks keanekaragaman $(\mathrm{H})$ menurut Shannon \& Weaner (Magurran, 1988), dengan rumus sebagai berikut:

Indeks keanekaragaman spesies $\left(\mathrm{H}^{\prime}\right)=-\sum_{i=l}^{s}\left(\mathrm{P}_{\mathrm{i}}\right)\left(\ln \mathrm{P}_{\mathrm{i}}\right)$

Keterangan: $\mathrm{P}_{\mathrm{i}}=$ proporsi tiap spesies dan $\mathrm{In}=$ Logaritme natural (bilangan alami)

Kriteria nilai indeks menurut Shannon dalam Odum (1996):

$\mathrm{H}^{\prime}<1=$ komunitas biota tidak stabil atau kualitas air tercemar berat

$1<\mathrm{H}^{\prime}<3=$ stabilitas komunitas biota sedang atau air tercemar sedang

$\mathrm{H}^{\prime}>3$ = stabilitas komunitas biota dalam kondisi prima (stabil) atau kualitas air bersih.

Untuk menentukan tingkat kemerataan spesies digunakan indeks kemerataan Shannon (E) (Magurran, 2004), sebagai berikut: Indeks kemerataan spesies $(E)=H / \ln (S)$; di mana $S=$ jumlah spesies.

Sedangkan analisis statistik yang digunakan adalah program Statistika versi 6, Anova satu arah (one-way Anova) dan uji Duncan pada taraf kepercayaan $95 \%$ dipakai untuk mengetahui perbedaan kekayaan spesies, kelimpahan spesies, nilai keanekaragaman spesies dan kemerataan spesies pada setiap stasiun pengambilan sampel (StatSoft 2001; Ohsawa 2005).

\section{Hasil dan Pembahasan}

Berdasarkan hasil identifikasi didapatkan sebanyak 279 individu spesies serangga air yang dikoleksi dari 3 stasiun pengamatan. Jumlah spesies yang ditemukan sebanyak 22 spesies yang termasuk dalam 14 famili dan terdiri terdiri dari 5 ordo, yaitu Ephemeroptera, Plecoptera, Trichoptera, Hemiptera, dan Coleoptera. Ordo yang memiliki spesies paling banyak adalah Ephemeroptera yaitu 9 spesies, seperti yang ditunjukkan pada Tabel 1. Spesies yang paling banyak ditemukan ialah dari ordo hemiptera yaitu Gerris remigis (21,51\%), diikuti oleh Hydropsyche sp1(12,19\%) anggota ordo Trichoptera dan anggota ordo Ephemeroptera yaitu Stenonema sp1(10,39\%) .

Jumlah serangga air tertinggi terdapat pada stasiun 2, sebanyak 112 individu dengan kelimpahan relatif 40,14\%, diikuti stasiun 1 dengan kelimpahan 105 individu (37,63\%), sedangkan spesies serangga air di stasiun 3 paling sedikit dengan nilai kelimpahan 62 individu $(22,22 \%)$. Hasil yang diperoleh menggambarkan bahwa kelimpahan spesies bervariasi, ada yang ditemukan hanya pada satu stasiun, namun ada juga yang dapat ditemukan pada dua stasiun sampai tiga stasiun. Gerris remigis ialah spesies yang paling sering muncul pada setiap stasiun dan banyak ditemukan dengan presentasi 21,51\%, kemudian Hydropsyche sp1 12,19\% dan hanya muncul di stasiun 1 dan 2. Spesies yang paling sedikit ditemukan adalah Isonychia sp pada stasiun 1 , Acroneuria $\mathrm{sp}$ dan Psephenus $\mathrm{sp}$ pada stasiun 2 dengan presentasi masing-masing $0,36 \%$ dan $0,72 \%$.

Ordo yang paling dominan ditemukan saat pengambilan sampel yaitu Ephemeroptera dan Trichoptera, namun hanya hadir pada dua stasiun saja, yaitu pada stasiun 1 bagian hulu sungai dan stasiun 2 bagian tengah daerah aliran sungai. Hal ini disebabkan karena adanya penurunan kualitas air sungai yang dilihat berdasarkan kondisi fisik pada stasiun 3. Ordo Plecoptera, Ephemeroptera, dan Trichoptera sangat sensitif terhadap perubahan lingkungan, dan banyak di temukan pada kondisi air yang bersih, dingin, dan terdapat banyak oksigen terlarut (Chu dan Chutkomp, 1992).

Penelitian tentang serangga air di Sungai Mekong, Thailand yang dilakukan oleh Thani \& Phalaraksh (2008) melaporkan bahwa ordo yang paling banyak ditemukan yaitu ordo Ephemeroptera sebanyak 68\%. Hasil penelitian Salamah et al (2001) di sungai Kerian, Perak, Malaysia menyatakan bahwa ordo Ephemeroptera yang paling dominan ditemukan di aliran sungai dan jumlahnya lebih dari setengah total individu yang ditemukan yaitu 52,04\%. Penelitian lainnya dilakukan di Hulu Terengganu mendapatkan bahwa beberapa famili ordo Ephemeroptera lebih banyak di temukan di bagian hilir sungai baik di Sungai Peres maupun di Sungai Bubu (Wahizatul dan Ahmad, 2011). Kehadiran Ordo Ephemeroptera yang melimpah pada suatu ekosistem sungai berpotensi sebagai bioindikator ekosistem sungai yang tidak tercemar (Armitage et al., 1983). Ordo ini biasanya hidup pada habitat yang tidak tercemar dan kisaran DO air antara 4-10 ppm (Kellogg, 1994). Hal ini sesuai dengan hasil pengukuran DO pada semua lokasi yang berkisar 6,75-7,86 ppm.

Keanekaragaman spesies tertinggi ditemukan di stasiun 1 dan diikuti oleh stasiun 2 dan keanekaragaman spesies terendah ditemukan di stasiun 3. Kemerataan spesies yang tertinggi ditemukan di stasiun 1 kemudian diikuti oleh stasiun 3 dan kemerataan spesies terendah ditemukan di stasiun 2. Nilai kelimpahan, kekayaan dan keanekaragaman spesies di stasiun 1 dan stasiun 2 tidak berbeda nyata, namun nilai kedua stasiun ini berbeda nyata terhadap stasiun 3 (Tabel 2 dan Gambar 1).

Hasil uji statistik menunjukkan bahwa kelimpahan spesies, kekayaan spesies, dan keanekaragaman spesies berbeda nyata antar stasiun pengamatan (Anova: F2;9 = 8,69, $\mathrm{p}<0,05$; Anova: F2;9 = 66,50, p < 0,005; Anova: F2;9 = 98,38, p < 0,05), sedangkan nilai kemerataan spesies tidak menunjukan perbedaan nyata (Anova: $\mathrm{F} 2 ; 9=0,28, \mathrm{p}>0,05)$ (Gambar 1). Kelimpahan, 
kekayaan dan keanekaragaman spesies serangga air pada stasiun 1 tidak berbeda nyata dengan stasiun 2, tetapi berbeda nyata dengan stasiun 3

(Gambar 1).

Tabel 1 - Kelimpahan dan kelimpahan relatif jenis dan ordo serangga air yang ditemukan pada tiga stasiun pengamatan di Sungai Pajowa

\begin{tabular}{llllllllll}
\hline No & Ordo/Spesies & Sta 1 & $\%$ & Sta 2 & $\%$ & Sta 3 & $\%$ & Jml & $\%$ \\
\hline & Trichoptera & & & & & & & & \\
1 & Hydropsyche sp1 & 11 & 3,94 & 23 & 8,24 & 0 & 0,00 & 34 & 12,19 \\
2 & Hydropsyche sp2 & 0 & 0,00 & 14 & 5,02 & 2 & 0,72 & 16 & 5,73 \\
3 & Polycentropus sp & 7 & 2,51 & 10 & 3,58 & 0 & 0,00 & 17 & 6,09 \\
4 & Rhyacophila sp & 0 & 0,00 & 9 & 3,23 & 0 & 0,00 & 9 & 3,23 \\
5 & Chimarra sp & 0 & 0,00 & 5 & 1,79 & 0 & 0,00 & 5 & 1,79 \\
6 & Psilotreta sp & 0 & 0,00 & 5 & 1,79 & 0 & 0,00 & 5 & 1,79 \\
& Ephemeroptera & & & & & & & & \\
7 & Stenonema sp1 & 26 & 9,32 & 3 & 1,08 & 0 & 0,00 & 29 & 10,39 \\
8 & Stenonema sp2 & 6 & 2,15 & 2 & 0,72 & 0 & 0,00 & 8 & 2,87 \\
9 & Rhithrogena sp & 5 & 1,79 & 0 & 0,00 & 0 & 0,00 & 5 & 1,79 \\
10 & Stenonema sp3 & 2 & 0,72 & 0 & 0,00 & 2 & 0,72 & 4 & 1,43 \\
11 & Maccaffertium sp & 3 & 1,08 & 0 & 0,00 & 0 & 0,00 & 3 & 1,08 \\
& Maccaffertium & & & & & & & & \\
12 & sp1 & 1 & 0,36 & 0 & 0,00 & 0 & 0,00 & 1 & 0,36 \\
13 & Drunella sp1 & 11 & 3,94 & 8 & 2,87 & 0 & 0,00 & 19 & 6,81 \\
14 & Drunella sp2 & 7 & 2,51 & 4 & 1,43 & 0 & 0,00 & 11 & 3,94 \\
15 & Isonychia sp & 2 & 0,72 & & 0,00 & 0 & 0,00 & 2 & 0,72 \\
& Plecoptera & & & & & & & & \\
17 & Acroneuria sp & 0 & 0,00 & 1 & 0,36 & 0 & 0,00 & 1 & 0,36 \\
& Coleoptera & & & & & & & & \\
18 & Zaitzevia sp & 4 & 1,43 & 11 & 3,94 & 0 & 0,00 & 15 & 5,38 \\
19 & Psephenus sp & 0 & 0,00 & 2 & 0,72 & 0 & 0,00 & 2 & 0,72 \\
& Hemiptera & & & & & & & & \\
20 & Gerris remigis & 10 & 3,58 & 13 & 4,66 & 37 & 13,26 & 60 & 21,51 \\
& Hydrometra & & & & & & & & \\
21 & stagnorum & 5 & 1,79 & & 0,00 & 21 & 7,53 & 26 & 9,32 \\
Total & Mesovelia sp & 5 & 1,79 & 2 & 0,72 & 0 & 0,00 & 7 & 2,51 \\
\hline & & 105 & 37,63 & 112 & 40,14 & 62 & 22,22 & 279 & 100,00 \\
\hline
\end{tabular}

Tabel 2 - Rata-rata dan standar deviasi struktur komunitas Serangga air yang ditemukan di Sungai Pajowa.

\begin{tabular}{cccccc}
\hline \multirow{2}{*}{ Lokasi } & Jumlah & \multicolumn{4}{c}{ Rata-rata dan Standar Deviasi } \\
\cline { 3 - 7 } & Titik & Kelimpahan sp & Kekayaan sp & Keanekaragaman sp & Kemerataan sp \\
\hline Stasiun 1 & 4 & $26,25 \pm 2,50$ & $8,00 \pm 0,82$ & $1,90 \pm 0,13$ & $0,92 \pm 0,03$ \\
Stasiun 2 & 4 & $28,00 \pm 6,73$ & $8,50 \pm 1,00$ & $1,89 \pm 0,10$ & $0,89 \pm 0,05$ \\
Stasiun 3 & 4 & $15,50 \pm 3,42$ & $2,50 \pm 0,58$ & $0,79 \pm 0,15$ & $0,90 \pm 0,07$ \\
\hline
\end{tabular}

Kelimpahan, kekayaan dan keanekaragaman spesies serangga air distasiun 2 dan 1 banyak ditemukan karena didukung oleh kondisi habitat. Berbagai ukuran tumpukan batuan membentuk beragam kondisi habitat sehingga menyediakan tempat yang nyaman bagi beraneka jenis serangga air yang berlindung di sela batuan atau yang hidup menempel pada batuan agar tidak terhanyut oleh derasnya arus sungai. Kondisi tersebut umumnya menunjang keanekaragaman hewan serangga air yang tinggi itu sebabnya keanekaragaman di stasiun 2 dan 1 paling tinggi. Hasil penelitian ini sejalan dengan penelitian yang dilakukan oleh Wahizatul dan Ahmad, (2011) bahwa kelimpahan serangga air lebih tinggi di hulu sungai dibandingkan dengan hilir sungai. 

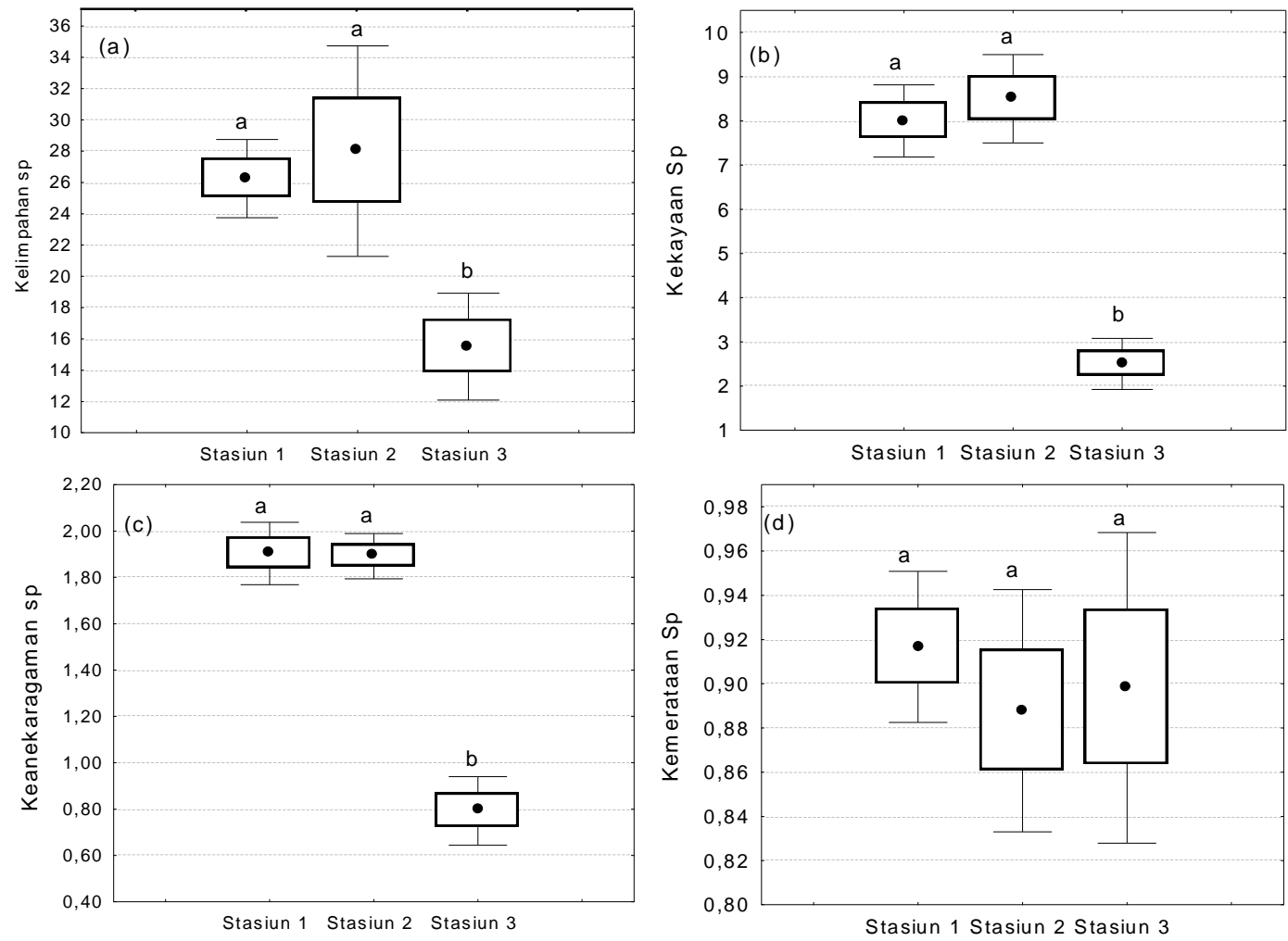

Ket: $(\bullet)$ : rata-rata, $(\square): \pm$ galat baku $( \pm \mathrm{SE}), \quad($ 工 $): \pm$ simpangan baku $( \pm \mathrm{SD})$, Huruf yang sama pada gambar yang sama tidak berbeda nyata menurut uji Duncan pada taraf kepercayaan $95 \%$

Gambar 1 - Struktur komunitas seranggga air pada tiga stasiun pengamataan di Sungai Pajowa (a): kelimpahan (b): kekayaan, (c): nilai

\section{Kesimpulan}

Jumlah serangga air yang ditemukan di Sungai Pajowa, Sulawesi Utara sebanyak 279 individu yang termasuk dalam 22 dan 14 famili serta 5 ordo. Spesies yang paling banyak ditemukan adalah Gerris remigis anggota ordo Hemiptera sedangkan ordo yang memiliki jumlah spesies paling banyak adalah Ephemeroptera. Kelimpahan dan kekayan serangga air tertinggi ditemukan di bagian tengah aliran sungai dengan kelimpahan spesies 28,00 dan kekayaan spesies 8,50 sedangkan keanekaragaman dan kemeratan spesies tertinggi terdapat pada bagian hulu sungai yaitu keanekaragaman spesies 1,90 dan kemerataan spesies 0,92. Kelimpahan, kekayaaan dan keanekaragaman spesies serangga air berbeda nyata antar stasiun pengamatan, sedangkan kemerataan spesies tidak menunjukkan perbedaan yang nyata.

\section{Daftar Pustaka}

Armitage, P. D., Moss, D., Wright, J. F and Furse, M. T. (1983). The performance of a new biological water quality score system based on macroinvertebrates over a wide range of unpolluted running-water sites. Water Research.Universiti Malaysia Terengganu.

Borror, B. J, C.A. Triplehorn \& N.F. Johnson. 1992. Pengenalan Pelajaran Serangga. ed. Ke-6. Gajah Mada University Press, Yokyakarta. Indonesia

Bugguide, 2012. Identification, Images, and Information For Insects, Spiders \& Their Kin For the United States and Canada. Canada http://bugguide.net/node/view/15740. diakses tanggal 18 September 2012

Che Salmah M.R., Amelia Z.S. and Abu Hassan A, 2001.Preliminary Distribution of Ephemeroptera, Plecoptera and Trichoptera (EPT) in Kerian River

*Corresponding author: Jurusan Biologi FMIPA UNSRAT, Jl. Kampus Unsrat, Manado, Indonesia 95115; Email address: gladysleba@yahoo.com Published by FMIPA UNSRAT (2013) 
Basin, Perak, Malaysia. School of Biological Sciences, Universiti Sains Malaysia, 11800 Minden, Penang, Malaysia.

Chu HF, Cutkomp LK. 1992. How To Know The Immature Insects. Dubuque: Wm. C. Brown Communications, Inc.

Grzela, T. K., P. Wright. 2003. Aquatic Organisms Of The City Of Greater Sudbury Area Lakes. Instituto Nacional de Pesquisas da Amazonia. http://www.scielo.br/scielo.php?script=sci_artte xt\&pid=S0044-5967200700400021>. Diakses September 2012.

Isara Thani and Chitchol Phalaraksh, 2008. A Preliminary Study of Aquatic Insect Diversity and Water Quality of Mekong River, Thailand. Department of Biology, Faculty of Science, Chiang Mai University, Chiang Mai 50200, Thailand.

Jana S, Pahari PR, Dutta TK, Bhattacharya T, 2009. Diversity and community structure of aquatic insects in a pond in Midnapore town, West Bengal, India.

Kellogg L,1994. Monitor's guide to aquatic macroinvertebrates. Gaithersburg, MD: Izaak Walton League of America.

Magurran AE. 1988. Ecological Diversity And Its Measurements. London: Croom Helm Limited. London.
Magguran, AE. 2004. Measuring Biological Diversity. Malden; Blackwell Publishing

Ohsawa M. 2005. Species richness and composition of Curculionidae (Coleoptera) in a conifer plantation, secondary forest, and old-growth forest in the central mountainous region of Japan. Ecology Research 20: 632-645.

Odum, E. P. 1996. Dasar-Dasar Ekologi. Gadjah Mada University Press. Yogyakarta

Popoola and A. Otalekor. 2011. Analysis of Aquatic Insects' Communities of Awba Reservoir and its Physico-Chemical Properties. Department of Zoology, University of Ibadan, Oyo State, Nigeria.

StatSoft 2001.Stastistica for windows, 6.0 statsoft Inc. Tulsa: Oklohoma.

Troutnut, 2012. Aquatic Insect Encyclopedia. http://www.troutnut.com/ . diakses Agustus 2012

Wahizatul, A. A., Long, S. H. And Ahmad, A, 2011.Composition And Distribution Of Aquatic Insect Communities In Relation To Water Quality In Two Freshwater Streams Of Hulu Terengganu, Terengganu. Department of Biological Sciences, Faculty of Science and Technology, Universiti Malaysia Terengganu, 21030 Kuala Terengganu, Terengganu, Malaysia. 